\title{
Comparison of 3D and 2D characterization of spinal geometry from biplanar X-rays: a large cohort study
}

\author{
Zongshan $\mathrm{Hu}^{1,2,3 \#}$, Claudio Vergari ${ }^{4 \#}$, Laurent Gajny ${ }^{4}$, Zhen Liu ${ }^{1}$, Tsz-Ping Lam $^{2,3}$, Zezhang Zhu ${ }^{1,3}$, \\ Yong Qiu ${ }^{1,3}$, Gene C. W. Man ${ }^{2,3}$, Kwong-Hang Yeung ${ }^{3,5}$, Winnie C. W. Chu, ${ }^{3,5}$ Jack C. Y. Cheng, ${ }^{2,3}$, \\ Wafa Skalli ${ }^{4}$
}

\begin{abstract}
${ }^{1}$ Department of Spine Surgery, Drum Tower Hospital of Nanjing University Medical School, Nanjing, China; ${ }^{2}$ Department of Orthopaedics and Traumatology, The Prince of Wales Hospital, The Chinese University of Hong Kong, Hong Kong, China; ${ }^{3}$ The Joint Scoliosis Research Center of the Chinese University of Hong Kong-Nanjing University, Faculty of Medicine, The Chinese University of Hong Kong, Hong Kong, China; ${ }^{4}$ Arts et Métiers Institute of Technology, Université Sorbonne Paris Nord, Institut de Biomécanique Humaine Georges Charpak (IBHGC), HESAM Université, Paris, France; ${ }^{5}$ Department of Imaging and Interventional Radiology, The Prince of Wales Hospital, The Chinese University of Hong Kong, Hong Kong, China
\end{abstract}

\#These authors contributed equally to this work.

Correspondence to: Jack C. Y. Cheng. Department of Orthopaedics and Traumatology, Faculty of Medicine, The Chinese University of Hong Kong, The Prince of Wales Hospital, Shatin, Hong Kong, China. Email: jackcheng@cuhk.edu.hk; Wafa Skalli. Arts et Métiers Institute of Technology, Université Sorbonne Paris Nord, Institut de Biomécanique Humaine Georges Charpak (IBHGC), HESAM Université, 151, Boulevard de l'Hôpital, 75013 Paris, France. Email: wafa.skalli@ensam.eu.

Background: Biplanar X-ray system providing anteroposterior and sagittal plane with an ultra-low radiation dose and in weight-bearing position is increasingly used for spine imaging. The original threedimensional (3D) reconstruction method from biplanar X-rays has been widely used for clinical parameters, however, the main issue is that manual adjustments of the $3 \mathrm{D}$ model was quite time-consuming and limited to thoracolumbar spine. A quasi-automated 3D reconstruction method of the spine from cervical vertebra to pelvis was proposed, which proved fast and accurate in 57 patients with adolescent idiopathic scoliosis. The aim of this study was to compare the newly developed technique of quasi-automatic 3D measurement with classical 2D measurements in a large cohort.

Methods: A total of 494 adults with biplanar EOS X-ray scanning were included in this study and divided into health and deformity group according to the presence of spinal deformity. The proposed method of quasi-automatic 3D measurement was applied to all these subjects. The radiographic parameters included: thoracic kyphosis (TK), lumbar lordosis (LL), pelvic incidence (PI), pelvic tilt (PT), sagittal vertical axis (SVA), T1 pelvic angle (TPA) in sagittal plane, and cobb angle in coronal plane. Comparison was made between quasi-automatic and manual measurement.

Results: The mean age was $53.7 \pm 19.9$ years old. In the whole population, the mean differences between the two methods were $3.9^{\circ}$ for TK $\left(30.5^{\circ} \pm 9.9^{\circ}\right.$ vs. $\left.26.5^{\circ} \pm 9.3^{\circ}, \mathrm{P}<0.001\right),-5.2^{\circ}$ for $\mathrm{LL}\left(-47.5^{\circ} \pm 11.2^{\circ}\right.$ vs. $\left.-42.4^{\circ} \pm 11.0^{\circ}, \mathrm{P}<0.001\right), 3.6^{\circ}$ for PI $\left(46.9^{\circ} \pm 10.3^{\circ}\right.$ vs. $\left.43.9^{\circ} \pm 10.3^{\circ}, \mathrm{P}<0.001\right),-0.2^{\circ}$ for $\mathrm{PT}\left(11.9^{\circ} \pm 7.7^{\circ}\right.$ vs. $\left.12.0^{\circ} \pm 8.2^{\circ}, \mathrm{P}=0.328\right),-2.1 \mathrm{~mm}$ for SVA $(15.7 \pm 26.2$ vs. $17.8 \pm 26.3 \mathrm{~mm}, \mathrm{P}=0.221)$ and $-1.1^{\circ}$ for $\mathrm{TPA}\left(9.0^{\circ} \pm 7.6^{\circ}\right.$ vs. $\left.10.1^{\circ} \pm 7.8^{\circ}, \mathrm{P}=0.051\right)$. The deformity group had similar mean differences with the asymptomatic group with the values ranged from $-4.1^{\circ}$ to $3.8^{\circ}$ for sagittal parameters. The mean differences of Cobb angle were $1.9^{\circ}$ for patients with Cobb angle $<30^{\circ}$ and $2.3^{\circ}$ for patients with Cobb angle $>30^{\circ}$, respectively. Correlation analysis showed $\mathrm{r} 2$ for all clinical parameters ranged from 0.667 to 0.923 . On average, the new method takes 5 minutes to compute all the parameters for one case.

Conclusions: In conclusion, this ergonomic and efficient quasi-automatic method for full spine proved fast and accurate measurement in a large population, which showed great potential in extensive clinical application. 
Keywords: Scoliosis; spine; three-dimensional reconstruction (3D reconstruction); automatic measurement; sagittal parameter

Submitted Jul 14, 2020. Accepted for publication Mar 22, 2021.

doi: $10.21037 /$ qims-20-861

View this article at: http://dx.doi.org/10.21037/qims-20-861

\section{Introduction}

Scoliosis is a complex three-dimensional (3D) deformity of the spine, which is characterized by a curvature in the coronal plane, which is usually quantified by Cobb angle, but also by a malalignment in the sagittal plane and rotation in the axial plane (1). 3D reconstruction techniques facilitate quantitative assessment, prognostication of deformity progression as well as assisting clinical management from bracing to surgical decision (2-4).

With the development of low-dose biplanar imaging system (EOS Imaging, Paris), 3D reconstruction of the thoracolumbar spine can be achieved with the bundled SterEOS software based on statistical modeling and bone shape recognition which is limited by the slow reconstruction and operator dependency. While endplate digitization is widely used for clinical parameters measurements (Cobb angle, kyphosis, lordosis), feedback from operators and radiology technicians is that manual adjustments of the $3 \mathrm{D}$ model is often required routinely. Previous studies reported that a number of radiographic parameters of the spine and pelvis, including thoracic kyphosis (TK), lumbar lordosis (LL), pelvic incidence (PI), pelvic tilt (PT), sagittal vertical axis (SVA) as well as T1 pelvic angle (TPA), play a role in pain and disability, and measuring health-related quality of life (HRQoL) in patients with spinal deformity (5-7). Therefore, there is a growing need to enhance the efficiency of the tedious daily measurement.

Recently, a quasi-automatic $3 \mathrm{D}$ reconstruction and measurement of spine has been proposed, which has been validated and proved fast and accurate in 57 patients with adolescent idiopathic scoliosis with less than 2.5 minutes per case, thus contributed a remarkable step towards full automatization of $3 \mathrm{D}$ reconstruction of the spine for wider applications (8). Nevertheless, 2D measurements are still considered the golden standard in clinical routine. Therefore, the objective of this study was to compare manual measured $2 \mathrm{D}$ spinopelvic parameters with those measured using the validated quasi-automatic $3 \mathrm{D}$ reconstruction measurements in a large cohort.

\section{Methods}

\section{Subjects}

A total of 494 adults aged from 20 to 89 years old who underwent biplanar X-ray scanning (EOS system, EOS Imaging, Paris, France) were included in this study, and divided into seven age groups (Table 1). Subjects were all interviewed by trained medical staffs following strict protocols with criteria. The exclusion criteria were as follows: (I) history of neuromuscular disorders or congenital anomalies; (II) previous spine, pelvis or lower-limb pathology that could affect the spine; (III) previous surgery on spine, pelvis or lower limb; or (IV) pregnancy (9). Then the subjects divided into asymptomatic (Group A) and scoliosis (Group S) group according to the presence of spinal deformity (Cobb angle $>10^{\circ}$ ).

\section{$3 D$ reconstruction}

A quasi-automatic $3 \mathrm{D}$ reconstruction and measurement of the spine was carried out in four steps using previously proposed method (10). Briefly, the operator started by identifying the acetabula, sacral endplate and the spinal midline through the center of all vertebral bodies, from the tip of the odontoid process to L5, on the frontal and lateral radiographs. Secondly, the operator marked the upper endplate of C7 and lower endplate of T12 on the sagittal view, as well as the upper and lower end vertebrae of the scoliotic curve, when present, on coronal curve. Then, an automatic algorithm provided an initial solution of $3 \mathrm{D}$ reconstruction based on the method of transversal and longitudinal inferences (Figure 1) (11).

\section{Radiographic parameters}

The following radiographic parameters were automatically computed from the $3 \mathrm{D}$ reconstruction: TK, LL, PI, PT, 
Table 1 Demographic distribution of study participants

\begin{tabular}{lccc}
\hline Parameters & Female $(\mathrm{n}=271)$ & Male $(\mathrm{n}=223)$ & 31 \\
\hline Age $20-29$ & 41 & 31 & 72 \\
Age 30-39 & 40 & 32 & 71 \\
Age 40-49 & 39 & 32 & 71 \\
Age 50-59 & 36 & 33 & 68 \\
Age 60-69 & 38 & 33 & 71 \\
Age 70-79 & 40 & 31 & 73 \\
Age 80-89 & 37 & $168.3 \pm 6.5$ & 68 \\
Body height $(\mathrm{cm})$ & $158.9 \pm 6.2$ & $68.8 \pm 7.8$ & $163.8 \pm 6.4$ \\
Body weight $(\mathrm{kg})$ & $54.7 \pm 7.4$ & & $61.3 \pm 7.6$ \\
\hline
\end{tabular}

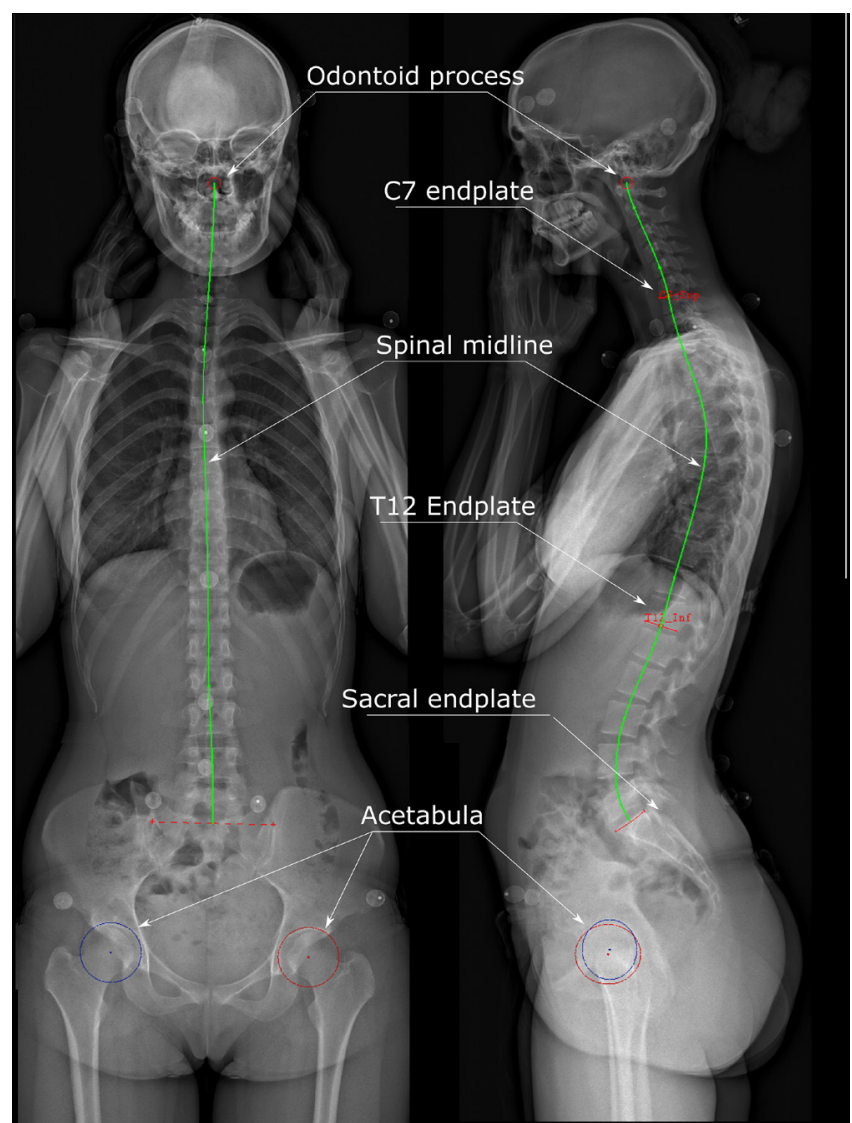

Figure 1 A bi-planar radiograph with posteroanterior and lateral view showed the $3 \mathrm{D}$ reconstruction procedures. $3 \mathrm{D}$, threedimensional.
SVA, TPA in sagittal plane, and cobb angle in coronal plane. The same parameters were also measured manually in $2 \mathrm{D}$ in the frontal and lateral radiographs. Comparison was made between quasi-automatic $3 \mathrm{D}$ and manual $2 \mathrm{D}$ measurement. The manual measurements were done by two orthopedic surgeons (LZ and TPL) with over 10 years of experiences. Intra- and inter-observer variations were conducted by two independent observers and estimated by using intraclass correlation coefficient (ICC), which were graded using previously described semi-quantitative criteria: excellent (ICC $\geq 0.9)$, good $(0.7 \leq \mathrm{ICC}<0.9)$, acceptable $(0.6<$ ICC $\leq 0.7)$, poor $(0.5 \leq$ ICC $<0.6)$, or unpredictable (ICC $<0.5)$.

\section{Statistical analysis}

All measurements were tabulated and analyzed using the SPSS version 22.0 software (SPSS Inc., Chicago, IL, USA). Normality of data distribution was checked with Kolmogorov-Smirnov test. Comparisons of mean values between quasi-automatic and manual measurements were performed using paired t-test if data was normally distributed or Mann-Whitney test (if data was not normally distributed). Bland-Altman analysis and Pearson correlations analysis were performed on the radiographic parameters between two measurements. Differences were detected as significant when a significance level (alpha) $<0.05$ was calculated. 
Table 2 Radiographic data of the two measurements

\begin{tabular}{|c|c|c|c|c|c|c|c|c|c|c|c|c|c|c|}
\hline Parameters & $\mathrm{TK}^{1}$ & $\mathrm{TK}^{2}$ & $\mathrm{LL}^{1}$ & $\mathrm{LL}^{2}$ & $\mathrm{Pl}^{1}$ & $\mathrm{Pl}^{2}$ & $\mathrm{PT}^{1}$ & $\mathrm{PT}^{2}$ & SVA $^{1}$ & SVA $^{2}$ & TPA $^{1}$ & $\mathrm{TPA}^{2}$ & Cobb $^{1}$ & Cobb $^{2}$ \\
\hline SD & 9.9 & 9.3 & 11.2 & 11.0 & 10.3 & 10.9 & 7.7 & 8.2 & 26.2 & 26.3 & 7.6 & 7.8 & 10.6 & 10.4 \\
\hline SE & 0.5 & 0.4 & 0.5 & 0.5 & 0.5 & 0.5 & 0.4 & 0.4 & 1.2 & 1.2 & 0.4 & 0.4 & 2.6 & 2.3 \\
\hline Min & -0.6 & 2.0 & -79.2 & -77.3 & 25.5 & 13.0 & -10.8 & -12.0 & -70.8 & -67.6 & -10.3 & -13.0 & 14.2 & 15.8 \\
\hline
\end{tabular}

${ }^{1}$, measured by quasi-automatic method; ${ }^{2}$, measured by manual method. TK, thoracic kyphosis; LL, lumbar lordosis; SS, sacral slope; PT, pelvic tilt; PI, pelvic incidence; SVA, sagittal vertical axis; TPA, T1 pelvic angle.

Table 3 Comparison of the radiographic values between automatic measurement and manual measurement in the whole cohort

\begin{tabular}{|c|c|c|c|c|c|c|c|}
\hline Parameters & TK & LL & $\mathrm{PI}$ & PT & SVA & TPA & Cobb \\
\hline Mean absolute error & 5.3 & 6.8 & 5.0 & 1.6 & 4.5 & 2.1 & 2.7 \\
\hline SD absolute error & 3.8 & 5.4 & 4.5 & 2.0 & 6.5 & 2.6 & 2.0 \\
\hline Coefficient of variation & 19.0 & 15.2 & 11.2 & 13.2 & 25.4 & 21.0 & 18.7 \\
\hline Percentage difference (\%) & 14.7 & 12.3 & 8.0 & 1.7 & 11.8 & 10.9 & 6.7 \\
\hline
\end{tabular}

TK, thoracic kyphosis; LL, lumbar lordosis; SS, sacral slope; PT, pelvic tilt; PI, pelvic incidence; SVA, sagittal vertical axis; TPA, T1 pelvic angle.

\section{Results}

A total of 494 subjects (female/male: 271/223) were enrolled in this study with a mean age of $53.7 \pm 19.9$ (range, 20-89) years old. Table 1 showed the age and gender distribution. The BMI was $24.1 \pm 6.8 \mathrm{~kg} / \mathrm{m}^{2}$. Among this large population, 442 subjects were included in Group A, and 52 in Group S with a mean Cobb angle of $31.4^{\circ} \pm 10.4^{\circ}$. The intra- and interobserver ICCs were from 0.667 to 0.923 , which suggested a good to excellent reliability of these measurements between the two observers.

In the whole population, the comparison between the two measurements of the mean values of TK, LL, PI, PT, SVA and TPA was shown in Table 2. Mann-Whitney test showed the comparison between the two measurements as follows: TK $(\mathrm{P}<0.001)$, LL $(\mathrm{P}<0.001)$, PI $(\mathrm{P}<0.001)$, PT $(\mathrm{P}=0.328)$, SVA $(\mathrm{P}=0.221)$, TPA $(\mathrm{P}=0.051)$. The mean differences were $3.8^{\circ}$ for $\mathrm{TK},-5.1^{\circ}$ for $\mathrm{LL}, 3.6^{\circ}$ for PI, -0.1 for PT, $-2.2 \mathrm{~mm}$ for SVA and $-1.1^{\circ}$ for TPA. The SD difference in LL was $7.7^{\circ}$, which was the largest among these parameters (Table 3).

In asymptomatic cohort, the mean differences between the two measurements were similar to the values in the whole population (Table 4). The mean differences of TK, LL, and PT in Group A was $0.1^{\circ}$ higher than those in the whole population, while PI and TPA were the same between the two cohorts. The Group S had similar mean differences with the values ranged from $-4.1^{\circ}$ to $3.8^{\circ}$ for sagittal parameters. In the coronal plane, the mean difference of Cobb angle between measurement methods was $1.9^{\circ}$, with a mean value of $1.6^{\circ}$ for patients with Cobb angle $<30^{\circ}$ and $2.3^{\circ}$ for patients with Cobb angle $>30^{\circ}$, respectively.

Figure 2 shows Bland-Altman graphs for the agreement between the quasi-automatic and manual method for all sagittal parameters. Correlation analysis showed $r^{2}$ for all radiographic parameters between two measurements ranged from 0.661 to 0.923 (Figure 3, $\mathrm{P}<0.01$ ). For an experienced operator, it took 5 minutes in average to obtain the $3 \mathrm{D}$ reconstruction of spine and pelvis, while the time consumed in traditional manual measurement was 15 minutes.

\section{Discussion}

This study represented a large-scale cross-sectional 
Table 4 Comparison of the radiographic values between automatic measurement and manual measurement in the asymptomatic group

\begin{tabular}{|c|c|c|c|c|c|c|}
\hline Parameters & TK & LL & $\mathrm{PI}$ & PT & SVA & TPA \\
\hline Mean absolute error & 5.4 & 6.8 & 5.1 & 1.6 & 4.6 & 2.1 \\
\hline SD absolute error & 3.7 & 5.2 & 4.3 & 2.1 & 6.5 & 2.5 \\
\hline Coefficient of variation & 18.8 & 15.2 & 11.1 & 13.2 & 25.4 & 21.0 \\
\hline
\end{tabular}

TK, thoracic kyphosis; LL, lumbar lordosis; SS, sacral slope; PT, pelvic tilt; PI, pelvic incidence; SVA, sagittal vertical axis; TPA, T1 pelvic angle.
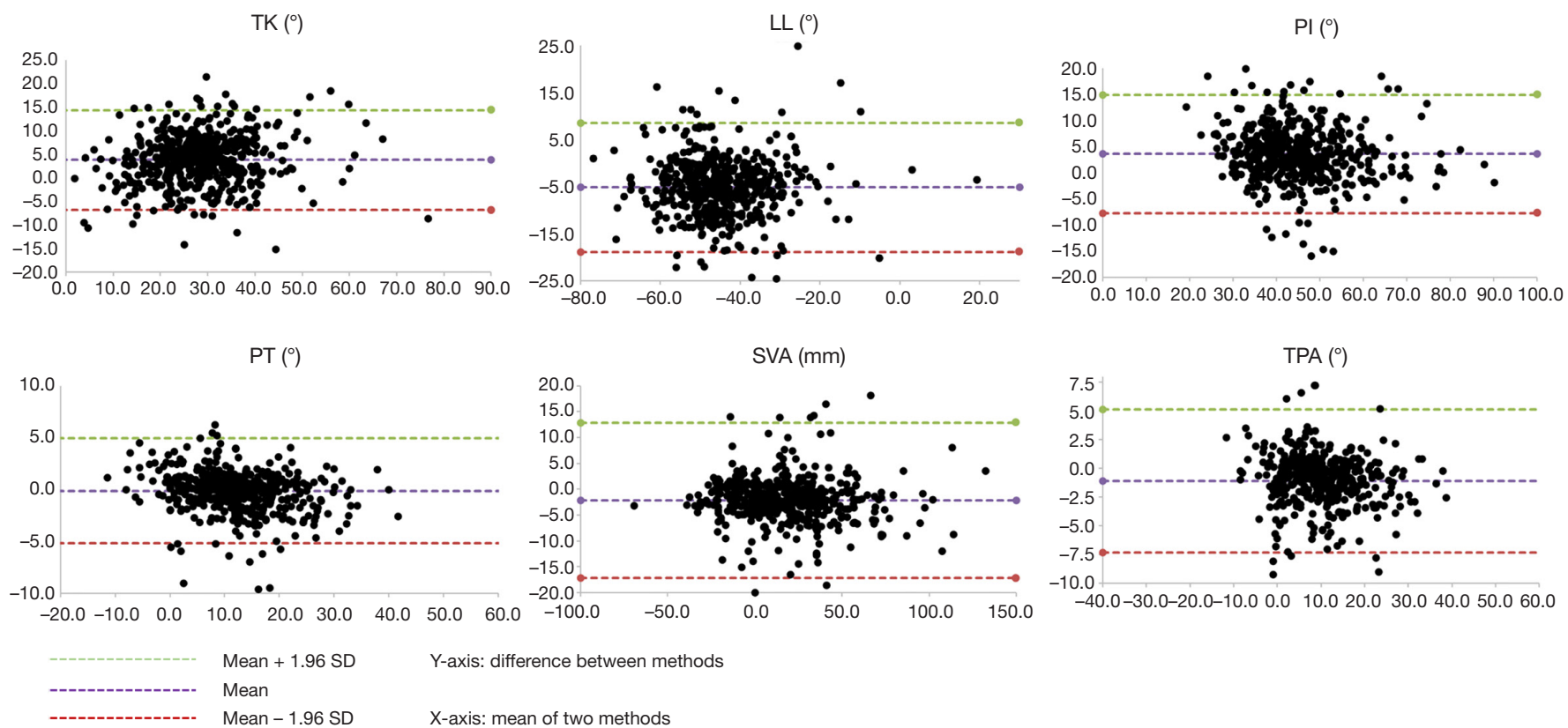

Figure 2 Bland-Altman plots for the agreement between the quasi-automatic and manual measurements for TK, LL, PI, PT, SVA and TPA. TK, thoracic kyphosis; LL, lumbar lordosis; PI, pelvic incidence; PT, pelvic tilt; SVA, sagittal vertical axis; TPA, T1 pelvic angle.

comparative analysis of quasi-automatic 3D measurement of full spine derived from EOS biplanar standing radiographs aged from 20 to 89 years old. Based on the findings, this new technique of quasi-automatic $3 \mathrm{D}$ reconstruction and measurement proved fast in a large population with a wide variety of spine morphologies across different ages. Furthermore, the geometrical parameters calculated from $3 \mathrm{D}$ reconstruction were consistent with $2 \mathrm{D}$ manual measurements.

The scientific and clinical importance of $3 \mathrm{D}$ reconstruction and measurement of the spine is largely increasing in recent years with the development of EOS biplanar low-dose X-ray radiography $(11,12)$. To have a better understanding of the initiation and progression of scoliosis as well as the optimistic surgical decisionmaking, the new 3D classification of AIS and key 3D index were proposed in recent years (2,13-15). However, the complexity and operator dependency of the original reconstruction method limited its extensive application in clinical routine. The novel approach allows for an accurate $3 \mathrm{D}$ reconstruction with a much shorter operator-time.

The Cobb angle measurement is calculated from the coronal spinal curvature, which is important to determine the curve pattern, severity of scoliosis and treatment 

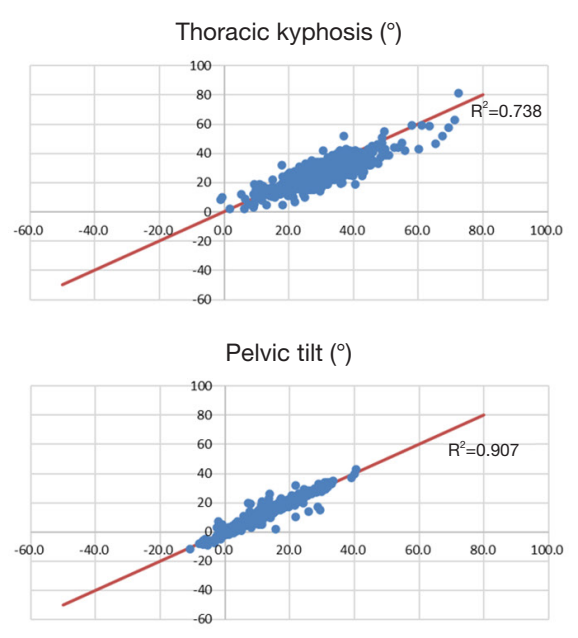

Y-axis: manual measurement; X-axis: automatic measurement
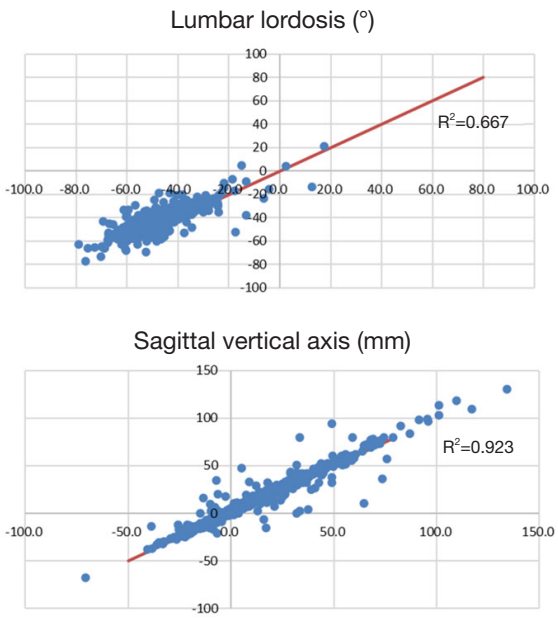
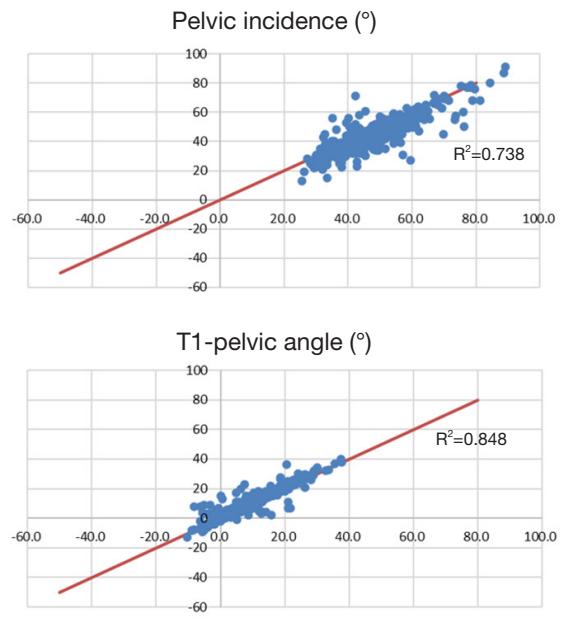

Figure 3 Scatter plots for correlation analysis in all radiographic parameters.

strategy. Therefore, an accurate measurement of Cobb angle is indispensable. In the current study, consistency between $2 \mathrm{D}$ and $3 \mathrm{D}$ Cobb angle measurements was tested; differences in Group S were $1.9^{\circ}$ in patients with Cobb angle smaller than $30^{\circ}$ and $2.3^{\circ}$ in patients with Cobb angle larger than $30^{\circ}$. Sardjono et al. reported an automatic Cobb angle determination and tested the accuracy in 36 AIS patients with a mean difference of $3.3^{\circ}(16)$. In a recent study, Zhang et al. proposed an automatic method for Cobb angle measurement and compare the results with $2 \mathrm{D}$ manual measurement in which the mean differences were $2.9^{\circ}$ in mild group (Cobb angle $<25^{\circ}$ ), $3.7^{\circ}$ in moderate group (Cobb angle between $25^{\circ}$ and $45^{\circ}$ ) and $3.9^{\circ}$ in severe group (Cobb angle $<45^{\circ}$ ), respectively (17). In addition, Safari et al. newly developed a semi-automatic algorithm to estimate Cobb angle, which was user-friendly and reliable with a correlation coefficient of 0.81 (18).

On the other hand, a number of studies have shown that the sagittal parameters of the spine and pelvis play an important role in evaluating HRQoL in patients with spinal deformity (5-7). Safari et al. developed a deep learning tool for automatic measurement of sagittal parameters, and the results showed that the mean differences with manual measurements were for $5.5^{\circ} \mathrm{PI}, 2.7^{\circ}$ for PT and $5.0^{\circ}$ for spinosacral angle (18). Nevertheless, TK and LL were not assessed in their study; these parameters are difficult to estimate through automatic identification due to the low visibility at upper thoracic vertebrae overlapped by upper arm and lower lumbar vertebrae obstructed by iliac crest and intestine contents in the sagittal view. Galbusera et al. recently conducted a study of automatic analysis of spinal deformities, which presented that the standard deviation of TK and LL were $8.6^{\circ}$ and $11.5^{\circ}$, respectively (19). By contrast, the current study showed that the SD of TK and LL were $5.3^{\circ}$ and $6.8^{\circ}$, respectively, which revealed a good measurement performance in sagittal parameters, although disagreement between 2D and 3D LL was relatively high. This might be due to the shape and visibility of the sacral plateau, which can be difficult to digitize with a straight line, as it is done in the $2 \mathrm{D}$ measurement.

In addition to other angular sagittal parameter, the linear parameter SVA, which correlates with pain and poor HRQoL scores (20) was also validated in this study with a mean difference of $-2.1 \mathrm{~mm}$. Another study of automatic measurement for SVA reported the mean absolute error between automatic and manual methods ranged from 1.18 to $9.82 \mathrm{~mm}$ (21). As a global angular parameter, TPA quantifies spinopelvic malalignment and compensation through pelvic retroversion, which is not influenced by various postural compensatory mechanisms $(22,23)$. To the best our knowledge, this is the first study to develop a quasiautomatic measurement for TPA, and the mean difference was only $-1.1^{\circ}$.

This new method of quasi-automatic reconstruction and measurement, which was based on statistical inferences, image processing and machine learning, greatly reduce the time-consuming work of manual measurement on radiographs or adjusting each vertebra manually via elastic 
deformation for orthopedic surgeon and scientists (10). It took less than 5 minutes on average to generate a $3 \mathrm{D}$ reconstruction of pelvis and spine; this reconstruction allows the automatic computation of parameters on coronal, sagittal and axial plane. However, once the reconstruction is available, computation for novel parameters, such as TPA, can easily be implemented. On the other hand, manual 2D measurement usually takes more than 15 minutes to complete all the parameters ever for a welltrained operator (24), and the acquired measurements cannot be exploited further. In this study, the cohort was comprised of a variety of spine morphologies across wide age distribution, which proved the accuracy and clinical applicability of the proposed method in a large of young and elder, scoliotic and asymptomatic subjects.

However, there were still some limitations in this study. The proposed method as well as other automatic methods have natural difficulty in recognizing malformed vertebrae, thus the capacity of reconstruction and measurement for congenital and severe degenerative spinal deformity needs further improvement. Such cases were not included in this study. While a fully automatic method is ultimate goal in the upcoming era of artificial intelligence, the proposed method combining automatic processing and soft manual adjustment could be considered as a cogitative trade-off between automation and accuracy.

In conclusion, this ergonomic and efficient quasiautomatic method for full spine proved fast and accurate measurement in a large population, which showed great potential in extensive clinical application.

\section{Acknowledgments}

The authors are grateful to the ParisTech BiomecAM chair program on subject-specific musculoskeletal modelling (with the support of ParisTech and Yves Cotrel Foundations, Société Générale, Proteor and Covea).

Funding: None.

\section{Footnote}

Conflicts of Interest: All authors have completed the ICMJE uniform disclosure form (available at http://dx.doi. org/10.21037/qims-20-861). The authors have no conflicts of interest to declare.

Ethical Statement: This study was approved by the Joint Chinese University of Hong Kong-New Territories East
Cluster Clinical Research Ethics Committee (CREC Ref. No. 2017.689) and all participants provided written informed consent.

Open Access Statement: This is an Open Access article distributed in accordance with the Creative Commons Attribution-NonCommercial-NoDerivs 4.0 International License (CC BY-NC-ND 4.0), which permits the noncommercial replication and distribution of the article with the strict proviso that no changes or edits are made and the original work is properly cited (including links to both the formal publication through the relevant DOI and the license). See: https://creativecommons.org/licenses/by-nc-nd/4.0/.

\section{References}

1. Newton PO, Fujimori T, Doan J, Reighard FG, Bastrom TP, Misaghi A. Defining the "three-dimensional sagittal plane" in thoracic adolescent idiopathic scoliosis. J Bone Joint Surg Am 2015;97:1694-701.

2. Skalli W, Vergari C, Ebermeyer E, Courtois I, Drevelle X, Kohler R, Abelin-Genevois K, Dubousset J. Early detection of progressive adolescent idiopathic scoliosis: a severity index. Spine (Phila Pa 1976) 2017;42:823-30.

3. Ferrero E, Lafage R, Vira S, Rohan PY, Oren J, Delsole E, Guigui P, Schwab F, Lafage V, Skalli W. Threedimensional reconstruction using stereoradiography for evaluating adult spinal deformity: a reproducibility study. Eur Spine J 2017;26:2112-20.

4. Courvoisier A, Drevelle X, Vialle R, Dubousset J, Skalli W. $3 \mathrm{D}$ analysis of brace treatment in idiopathic scoliosis. Eur Spine J 2013;22:2449-55.

5. Glassman SD, Bridwell K, Dimar JR, Horton W, Berven S, Schwab F. The impact of positive sagittal balance in adult spinal deformity. Spine (Phila Pa 1976) 2005;30:2024-9.

6. Glassman SD, Berven S, Bridwell K, Horton W, Dimar JR. Correlation of radiographic parameters and clinical symptoms in adult scoliosis. Spine (Phila Pa 1976) 2005;30:682-8.

7. Schwab FJ, Blondel B, Bess S, Hostin R, Shaffrey CI, Smith JS, Boachie-Adjei O, Burton DC, Akbarnia BA, Mundis GM, Ames CP, Kebaish K, Hart RA, Farcy JP, Lafage V. Radiographical spinopelvic parameters and disability in the setting of adult spinal deformity: a prospective multicenter analysis. Spine (Phila Pa 1976) 2013;38:E803-12.

8. Amabile C, Pillet H, Lafage V, Barrey C, Vital J, Skalli $W$. A new quasi-invariant parameter characterizing the 
postural alignment of young asymptomatic adults. Eur Spine J 2016;25:3666-74.

9. Yukawa Y, Kato F, Suda K, Yamagata M, Ueta T, Yoshida $M$. Normative data for parameters of sagittal spinal alignment in healthy subjects: an analysis of gender specific differences and changes with aging in 626 asymptomatic individuals. Eur Spine J 2018;27:426-32.

10. Gajny L, Ebrahimi S, Vergari C, Angelini E, Skalli W. Quasi-automatic 3D reconstruction of the full spine from low-dose biplanar X-rays based on statistical inferences and image analysis. Eur Spine J 2019;28:658-64.

11. Labelle H, Aubin CE, Jackson R, Lenke L, Newton P, Parent S. Seeing the spine in 3D: how will it change what we do? J Pediatr Orthop 2011;31:S37-45.

12. Post $\mathrm{M}$, Verdun S, Roussouly P, Abelin-Genevois K. New sagittal classification of AIS: validation by $3 \mathrm{D}$ characterization. Eur Spine J 2019;28:551-8.

13. Kadoury S, Labelle H. Classification of three-dimensional thoracic deformities in adolescent idiopathic scoliosis from a multivariate analysis. Eur Spine J 2012;21:40-9.

14. Ilharreborde B, Dubousset J, Skalli W, Mazda K. Spinal penetration index assessment in adolescent idiopathic scoliosis using EOS low-dose biplanar stereoradiography. Eur Spine J 2013;22:2438-44.

15. Vergari C, Gajny L, Courtois I, Ebermeyer E, AbelinGenevois K, Kim Y, Langlais T, Vialle R, Assi A, Ghanem I, Dubousset J, Skalli W. Quasi-automatic early detection of progressive idiopathic scoliosis from biplanar radiography: a preliminary validation. Eur Spine J 2019;28:1970-6.

16. Sardjono TA, Wilkinson MH, Veldhuizen AG, van Ooijen PM, Purnama KE, Verkerke GJ. Automatic Cobb angle determination from radiographic images. Spine (Phila $\mathrm{Pa}$ 1976) 2013;38:E1256-62.

17. Zhang J, Lou E, Le LH, Hill DL, Raso JV, Wang Y. Automatic Cobb measurement of scoliosis based on fuzzy Hough Transform with vertebral shape prior. J Digit

Cite this article as: Hu Z, Vergari C, Gajny L, Liu Z, Lam TP, Zhu Z, Qiu Y, Man GCW, Yeung KH, Chu WCW, Cheng JCY, Skalli W. Comparison of $3 \mathrm{D}$ and 2D characterization of spinal geometry from biplanar X-rays: a large cohort study. Quant Imaging Med Surg 2021;11(7):33063313. doi: $10.21037 /$ qims-20-861
Imaging 2009;22:463-72.

18. Safari A, Parsaei H, Zamani A, Pourabbas B. A semiautomatic algorithm for estimating Cobb angle. J Biomed Phys Eng 2019;9:317-26.

19. Galbusera F, Niemeyer F, Wilke HJ, Bassani T, Casaroli G, Anania C, Costa F, Brayda-Bruno M, Sconfienza LM. Fully automated radiological analysis of spinal disorders and deformities: a deep learning approach. Eur Spine J 2019;28:951-60.

20. Lafage V, Schwab F, Skalli W, Hawkinson N, Gagey PM, Ondra S, Farcy JP. Standing balance and sagittal plane spinal deformity: analysis of spinopelvic and gravity line parameters. Spine (Phila Pa 1976) 2008;33:1572-8.

21. Weng CH, Wang CL, Huang YJ, Yeh YC, Fu CJ, Yeh CY, Tsai TT. Artificial intelligence for automatic measurement of sagittal vertical axis using ResUNet framework. J Clin Med 2019;8:1826.

22. Ryan DJ, Protopsaltis TS, Ames CP, Hostin R, Klineberg E, Mundis GM, Obeid I, Kebaish K, Smith JS, Boachie-Adjei O, Burton DC, Hart RA, Gupta M, Schwab FJ, Lafage V. T1 pelvic angle (TPA) effectively evaluates sagittal deformity and assesses radiographical surgical outcomes longitudinally. Spine (Phila Pa 1976) 2014;39:1203-10.

23. Protopsaltis T, Schwab F, Bronsard N, Smith JS, Klineberg E, Mundis G, Ryan DJ, Hostin R, Hart R, Burton D, Ames C, Shaffrey C, Bess S, Errico T, Lafage V. The T1 pelvic angle, a novel radiographic measure of global sagittal deformity, accounts for both spinal inclination and pelvic tilt and correlates with health-related quality of life. J Bone Joint Surg Am 2014;96:1631-40.

24. Humbert L, De Guise JA, Aubert B, Godbout B, Skalli W. $3 \mathrm{D}$ reconstruction of the spine from biplanar $\mathrm{X}$-rays using parametric models based on transversal and longitudinal inferences. Med Eng Phys 2009;31:681-7. 